\title{
Influence of Rural Financial Institutions on the Progress of Rural Technology
}

\author{
J.H. Liu \\ Huazhong Agricultural University, Wuhan, China \\ Hubei Engineering University, Xiaogan, China \\ C.J. Li \\ Huazhong Agricultural University, Wuhan, China
}

\begin{abstract}
Technological progress is the key factor to influence economic growth. This article uses Empirical Analysis to analyze the relationship between rural technological progress and rural financial institution and finds that there exists one-way causal relationship between them in China. The progress of rural technology can promote the development of rural financial institutions, but the development of rural finance has not brought the progress of rural technology. It is necessary to deepen the reform of rural financial institutions, to promote the progress of rural technology.
\end{abstract}

KEYWORD: Rural financial institutions; Rural technological progress; One-way causal relationship

\section{INTRODUCTION}

The financial development influences the economic growth mainly through capital accumulation and technological progress: the former only has level effect on economic growth, the latter is the key factor. In China, the speed of rural technological progress is too slowly to develop rural economic efficiently. Recently, the rural financial institutions have greatly pushed forward the development of the rural economic, but the rural technology cannot get enough support from the social resources and financial resources, mainly because of the imperfect rural financial system and ineffective rural financial institutions, which restrain the development of rural economy.

Many economists have done farther research on the influence which the development of the financial instruments and system may have on the country. King \& Levine (1993) points that the joiner wants to get higher profit level by proceeding the technological progress, but the innovation has risk as well. So the financial system accelerates the technological progress and economic growth by decentralization of the risk. Giuliano \& Ruiz-Arranz (2009) choose 100 developing countries as samples, research the relationship between the financial development and economic growth by using many different data, and finally find out that the growth of the financial development is a great distribution to remit the financing constraints of the companies, enhance the invest level, as a result, contribute to the economic growth. Stein (2002) points out that the smaller regional banks can use the soft information more effectively than big banks. Big banks may perform well as a whole, but they may cause the segmentation of the loan market. As for small banks, the relationship loan is more important, which is the advantage for them.

Zhang Jie (2008) believes that technological progress and technological efficiency are the two issues which influence the economic growth of China. The contribution that the development of the financial medium does to the productivity mainly comes from the improvement of technological efficiency. Cai Jiaming (2006) indicates that recently there are many weaknesses in the financial system in China, and the development of financial system has to rely on the technological innovation. Liu Fengchao \& Shen Neng (2007) use empirical test to investigate the relationship between the financial system development and technological progress in China, and find out that the financial development and technological progress are balanced equilibrium joint development in the long run, their relationship is positive correlation and interaction. Sun Wuqin \& Zhu Shunlin (2008) use the DEA-Malmuquist index and find out that the financial development can greatly enhance the productivity efficiency of technological innovation. Xiao Wen (2008) makes the empirical analysis by using the relative data in China from 1995 to 2007, and points that the relationship between technological innovation and the development of financial intermediaries and stock market is positive correlation. The development of financial intermediaries promotes 
technological innovation, the liquidity and size of the stock market are promotion to technological innovation. Liu Jia (2008) makes an empirical analysis and finds the organization and activeness of financial system do not have obvious impact on technological innovation. However, the improvement of efficiency which financial system promotes technological innovation root in the financial system enlarges the input of technology, but the management efficiency is decreasing.

Based on the above research about this topic, we can easily find out the development of rural financial system is important to rural technological innovation. The rural financial organizations are established mainly aiming at the actual situation of our countryside and they can promote the progress of all aspects in rural to some degree. Meanwhile the rural technological progress will perfect the rural financial system extremely efficiency. But in practice, there exist many problems in rural financial organizations. So we need to support the rural financial organization, continue to deepen the reform, perfect the rural financial organization, enhance the competitiveness of rural finance to a larger extent, increase its impact on rural technology, finally achieve the sustainable development of rural economy, and work out issues of agriculture, farmer and rural areas problem.

This article chooses the rural financial organization and rural technological progress as the research objects, makes empirical analysis on their relationship, studies the mechanism and characteristic of rural financial organization, puts forward that we can promote the rural technological progress to enhance sustainable development of rural financial organizations and perfect rural financial system, provides new development ideas about the distribution of rural financial organization and rural technological progress, enhances the relationship between these two issues, which can promote the rural financial organization serve for rural technological progress more efficiently and quickly, changes the one-way causation of these two issues, and contributes to the development of rural area in China.

\section{VARIABLES SELECTION AND DATA SOURCES}

\subsection{Variables selection}

\subsubsection{The total power of agricultural machinery (TPAM)}

The total power of agricultural machinery refers to the total power of power machineries of Agricultural, forest, animal husbandry and fishery, including tillage machineries, irrigation machineries, harvesting machineries, agricultural transport machineries, plant protection machineries, animal husbandry machineries, forestry machineries, fishery machineries and other agricultural machineries. This shows the progress of rural technology in theory, but the technology is not directly transformed into the farmers' productivity. It can greatly improve the agricultural land productivity, labor productivity, product commercialization and the utilization rate of resources to carry out technological transformation and upgrade of traditional agriculture with modern science and technology, Therefore, the degree of agricultural mechanization is the reasonable index to reflect the level of agriculture technology. This article selects agriculture machinery total power (TPAM) to measure the progress of rural technology.

\subsubsection{The rural financial interrelation ratio (RFIR)}

Financial interrelation ratio is the ratio of the value of financial assets and total economic activity in the country at a certain date. This article emphasizes on the influence on the progress of rural technology and the development of rural financial institutions. Therefore, the financial interrelations ratio (RFIR) is simplified to the rural financial institutions loans / rural GDP, which is used to measure the development of rural finance in china.

\subsection{Data Sources}

This article selects the time series data from 1990 to 2011, see Table 1.

Table 1 TPAM and RFIR 1990-2011

\begin{tabular}{|c|c|c|}
\hline Year & TPAM (Million kilowatts) & RFIR \\
\hline 1990 & 28708 & 0.256982511 \\
\hline 1991 & 29389 & 0.291773936 \\
\hline 1992 & 30308 & 0.377489177 \\
\hline 1993 & 31817 & 0.357675518 \\
\hline 1994 & 33803 & 0.276998285 \\
\hline 1995 & 36118 & 0.243252544 \\
\hline 1996 & 38547 & 0.273060749 \\
\hline 1997 & 42016 & 0.562720699 \\
\hline 1998 & 45208 & 0.446296145 \\
\hline 1999 & 48996 & 0.245687018 \\
\hline 2000 & 52574 & 0.424466206 \\
\hline 2001 & 55172 & 0.457257448 \\
\hline 2002 & 57930 & 0.508926289 \\
\hline 2003 & 60387 & 0.571837531 \\
\hline 2004 & 64028 & 0.514231394 \\
\hline 2005 & 68398 & 0.560543458 \\
\hline 2006 & 72522 & 0.645556615 \\
\hline 2007 & 76590 & 0.643773137 \\
\hline 2008 & 82190 & 0.644529498 \\
\hline 2009 & 87496 & 0.780487400 \\
\hline 2010 & 92781 & 0.818897864 \\
\hline 2011 & 97735 & 0.821337203 \\
\hline
\end{tabular}

Data sources: "China Statistical Yearbook". 


\section{EMPIRICAL ANALYSIS}

We should judge the trend of time series in the empirical analysis. First we take the log of the rural financial interrelation ratio (RFIR) and the total power of agricultural machinery (TPAM), and then observe the line chart Figure 1. From the figure, we can see that the two lines are both gradually increased, that is the rural financial interrelation ratio (RFIR) and the total power of agricultural machinery (TPAM) have the same trend and change regulation, which shows there are co-integration relationship between them.

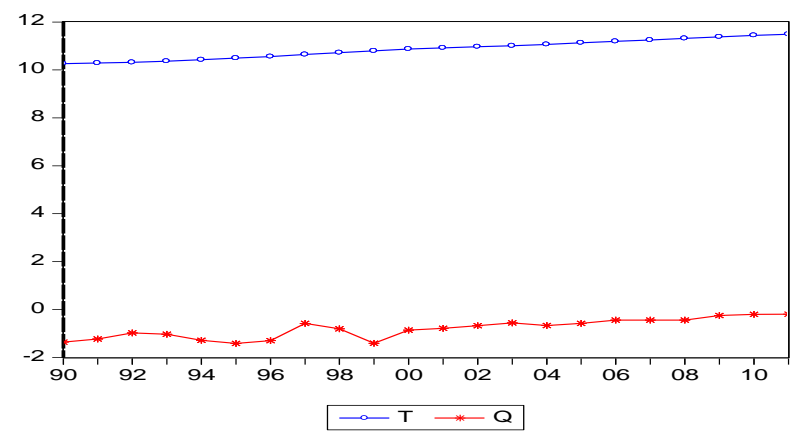

Figure 1 Logarithmic Line Chart of RFIR and TPAM

\subsection{Unit root test}

In order to avoid spurious regression, we should make stationary test on the data before series modeling. One of the common methods to test stationary of time series used is unit root test (Augmented Dickey-Full Test) proposed by Dickey (1979), simplified as ADF test.

Table 2 is the results of ADF unit root test using Eviews6.0. From the test results, ADF test values of the two series are greater than the critical values under $1 \%, 5 \%$ and $10 \%$ significant level, which suggest that the two series are non-stationary.

Table 2 ADF Test Results

\begin{tabular}{|c|c|c|c|c|c|}
\hline \multirow{2}{*}{ Sample } & \multirow{2}{*}{ ADF } & \multicolumn{3}{|c|}{ Critical Value } & \multirow{2}{*}{ P Value } \\
\cline { 3 - 6 } & & $1 \%$ & $5 \%$ & $10 \%$ & \\
\hline TPAM & -0.677884 & -4.498307 & -3.658446 & -3.268973 & 0.9609 \\
\hline RFIR & -3.752036 & -4.498307 & -3.658446 & -3.268973 & 0.0420 \\
\hline
\end{tabular}

In this regard, we should make first-order difference on two time series, the results of ADF test are as shown in table 3:

Table 3 ADF Test Results after First-order Difference

\begin{tabular}{|c|c|c|c|c|c|}
\hline \multirow{2}{*}{ Sample } & \multirow{2}{*}{ ADF } & \multicolumn{3}{|c|}{ Critical Value } & \multirow{2}{*}{ P Value } \\
\cline { 3 - 5 } & & $1 \%$ & $5 \%$ & $10 \%$ & \\
\hline TPAM & -4.642435 & -4.532598 & -3.673616 & -3.277364 & 0.0081 \\
\hline RFIR & -6.084918 & -4.616209 & -3.710482 & -3.29779 & 0.0007 \\
\hline
\end{tabular}

From the test results of Table 3, ADF test values of the two series are less than the critical values under $1 \%, 5 \%$ and $10 \%$ significant level, which suggest that two series are stationary, and they are first-order integration, which satisfy the premise of co-integration.

\subsection{Co-integration relation test}

Significance of co-integration test is to test whether a causal relationship described by the regression equation is spurious regression, i.e. to test whether there exists a stable relationship between the variables. This article uses ADF test proposed by Engel-Granger (1987) to conduct the co-integration test between RFIR and TPAM. By using the least square method, regression equation is established:

$$
\begin{array}{cc}
\log (\mathrm{TPAM})=11.54054+0.858236 \log (\mathrm{RFIR})+{ } & \hat{\mu}_{t} \\
\text { s.e. }=(0.095877) & (0.108232) \\
\mathrm{t}=(120.3685) & (7.929617) \\
\mathrm{R}^{2}=0.758684 & \mathrm{~F}=62.87883
\end{array}
$$

To eliminate the autocorrelation of residual series, we conduct ADF test on the residual series. Results are shown in Table 4:

Table 4 Results of Co-integration Relation Test

\begin{tabular}{|c|c|c|c|c|}
\hline \multirow{2}{*}{ ADF } & \multicolumn{3}{|c|}{ Critical Value } & \multirow{2}{*}{ P Value } \\
\cline { 2 - 4 } & $1 \%$ & $5 \%$ & $10 \%$ & \\
\hline-4.956318 & -4.498307 & -3.658446 & -3.268973 & 0.0041 \\
\hline
\end{tabular}

Results show there exists co-integration relationship because the residual series is stationary. Therefore, in the long run there is a significant positive correlation between RFIR and TPAM.

\subsection{Granger causality test}

The above test results show the existence of longterm stationary relationship between RFIR and TPAM, but cannot get their causal relationship, unable to judge whether the development of rural financial institutions affect the progress of rural technology, or the progress of rural technology affect rural financial development. The above ADF test has proven that the two variables are stationary at the first order, consistent with the conditions of Granger causality test. According to the AIC and SC criteria, selecting the optimal lag order as the first order, and using ordinary least squares (OLS), granger causality test results are as shown in Table 5.

Table 5 Results of Granger Causality Test

\begin{tabular}{|c|c|c|}
\hline Null hypothesis & Fstatistics & P value \\
\hline RFIR does not Granger Cause TPAM & 1.72250 & 0.2121 \\
\hline TPAM does not Granger Cause RFIR & 14.4337 & 0.0003 \\
\hline
\end{tabular}


Table 5 shows that RFIR is not the Granger cause of TPAM, but TPAM is the Granger cause of RFIR, namely agricultural technological progress can promote the development of rural finance, but rural financial development has not brought the progress of rural technology.

\section{CONCLUSIONS AND SUGGESTIONS}

In summary, there is one-way causal relationship between the development of rural technology and rural financial institutions. The progress of rural technology can promote the development of rural financial institutions, but the development of rural finance has not let to the progress of rural technology. This is consistent with the reality of our country. In the promotion of rural technology, agricultural production with low efficiency by manual operation, has transformed into mechanical operation with high efficient, which greatly improve the agricultural productivity, and promote the rapid growth of the rural economy. On this basis, the initial conditions of emergency and existence of the rural finance came into being, and the rural financial demand is becoming stronger, rural financial reform has achieved initial results. However, the development of rural finance has not led to the progress of rural technology. The main reason is that China's rural financial support for agricultural technological progress is not enough. In addition, farmers' loans, constrained by available funds, are rarely used for technological transformation, and not to promote the progress of agricultural technical. Because it is difficult to supervise the use of the loan credit institutions, farmers' loan for investment may also be used for other purpose, which will certainly not conducive to the sustainable development of rural economy and rural finance in the long run. Therefore, the development of rural financial institutions should regard promoting rural technological progress as the core and actively deepen the reform.

Firstly, providing financial support for the rural technology innovation. Together with the independent research and development, rural technology promotion requires cooperation of human, material and financial resources, especially requires a lot of financial support. Rural financial institutions should effectively play the role of financial support and technology screening, conducive to gathering rural dispersed, small funds into the most promising technological innovation projects. At the same time, through efficient allocation of capital, guide the path of rural technology innovation, provide financial support for rural technology popularization and application, and promote the rural technology development and progress.
Secondly, establishing agricultural insurance system and risk compensation mechanism. Without the rapid development of agricultural insurance, rural guarantee and rural futures are difficult to develop. The history of the reform and development of China's agricultural insurance tells us that the pure commercial insurance management cannot adapt to the development of rural economy, also need a policy-oriented agricultural insurance as a supplement. Agricultural insurance market is at the fledgling stage, which need the active guide of government and the support of rural financial institutions. At the same time, rural technological progress faces great risks, which will require the agricultural insurances to play the important role. Therefore, the agricultural insurances can be the intermediary and the connection points between the rural financial institutions and rural technological progress.

Finally, promoting the innovation of rural financial services in rural areas. Rural financial institutions should develop new products to meet the growing demand of new countryside and the needs of rural industrialization, Concerning innovative approaches, the first is innovating service areas, especially the middle business services, such as the collection of premiums; the second is innovating service tools, such as the modernization of payment systems and information networks platform; the third is innovating service products, such as syndicated loans, microcredit loans. Meanwhile, as the monopoly is detrimental to the efficiency of rural financial services, it is necessary to establish appropriate competition rural financial markets. On the premise of strict supervision, relaxing the access standards of rural financial market, developing newtype rural financial institutions, such as village banks and rural mutual cooperatives, building real competition bodies of rural finance, and promoting technological progress in the countryside.

\section{REFERENCES}

[1] WL ZHANG, HB LIU. 2008. Establishment of the Longterm mechanism to Increase farmer income supported by financial policy. Journal of Agrotechnical Economics,2, 80-84.

[2] FC LIU, ZHI SHEN. 2007. Decomposition granger causality test and co-integration between financial development and technological progress. Financial management, 3, 3-8.

[3] WQ SUN, SL ZHUN.2008. Efficiency of financial development to promote technological innovation, Statistical Research, 3, 46-50.

[4] JB ZHANG, GS YANG. 2010. An Empirical Study on the relationship between rural financial development and rural economy, Journal of Shandong University, 4, 1-9.

[5] ZP LI. 2012.Financial difficulties, the financial deepening and progress of rural technology in China, Jianghan Tribune, 6, 44-47 